\title{
Angiogenic potential of the cerebrospinal fluid (CSF) of patients with high-grade gliomas measured with the chick embryo chorioallantoic membrane assay (CAM).
}

\author{
Mariana Sinning ${ }^{1}$, René Letelier ${ }^{2}$, Carlos Rosas ${ }^{2}$, Marcela Fuenzalida ${ }^{2}$, David Lemus ${ }^{2}$ \\ 1. Neurology and Neurosurgery Department of the Hospital Clínico de la Universidad de Chile \\ 2. Experimental Embryology Laboratory, Morphology Program (ICBM), Faculty of Medicine, University of Chile.
}

\begin{abstract}
:
High-grade gliomas are highly vascularized tumors. Neo-angiogenesis plays a key role in tumor growth and resistance to therapy. A cerebrospinal fluid (CSF) sample could be a useful way to obtain pro-angiogenic predictive or prognostic markers at different stages of the disease. As a first step we looked for pro-angiogenic activity in the CSF of patients with high-grade gliomas. We performed the chicken embryo chorio-allantoic membrane (CAM) assay to study the angiogenic potential of the cerebrospinal fluid (CSF), obtained either by lumbar puncture (LP) or craniotomy from six patients with high-grade brain tumors (three glioblastoma (WHO grade IV), one anaplastic oligodendroglioma (WHO grade III), two anaplastic ganglioglioma (WHO grade III)), and four healthy controls. Significantly increased neo-angiogenesis was observed on the surface of the growing CAM in the 6 patients with high-grade gliomas compared to controls (3.69 \pm 1.23 versus $2.16 \pm 0.97$ capillaries per area (mean $\pm \mathrm{SD}$ ), $\mathrm{p}<0.005$ ). There was no statistical difference related to the hystological grade of the tumor (WHO grade III or IV), previous treatment (radio-chemotherapy plus temozolomide, temozolomide alone or no treatment), or the site of CSF sample (surgery or lumbar puncture). Our results suggest a pro-angiogenic potential in the CSF of patients with high-grade gliomas.
\end{abstract}

Key words: angiogenesis, cerebrospinal fluid, glioblastoma, high-grade glioma,

\section{INTRODUCTION}

High-grade gliomas are lethal cancers. According to the World Health Organization (WHO) classification, they include glioblastomas (WHO grade IV), anaplastic astrocytomas, anaplastic oligodendrogliomas and anaplastic oligoastrocytomas (WHO grade III). Despite recent advances in surgery, radiotherapy and chemotherapy, the overall survival reaches 15 months for glioblastoma (Stupp et al, 2009), 3-4 years for anaplastic astrocytoma and 4-5 years for anaplastic oligodendroglioma. The neuronal-glial tumor, ganglioglioma, is composed of neoplastic mature ganglion cells and neoplastic glial cells; the latter can develop anaplastic features as in anaplastic ganglioglioma (WHO grade III). These are rare neuroepitelial tumors with a better prognosis than pure highgrade gliomas (Luyken, 2004).

Essentially all patients with high-grade gliomas develop recurrent or progressive disease after the initial therapy. The overall survival for patients after this recurrence is 6 months. In 2007 in a phase II trial with bevacizumab and irinotecan, Vredenburgh showed an overall survival of 10 months (Vredenburgh, 2007) for patients with recurrent disease. Since then, antiangiogenic therapy with bevacizumab, a humanized monoclonal antibody that inhibits the vascular endothelial growth factor (VEGF), is an option for the treatment of glioblastoma recurrence. But only between $28 \%$ and $37 \%$ of the treated patients reach an objective response with bevacizumab (Friedman, 2009; Kreisl, 2009).

The search for new tumor markers for prognosis and predictor purposes for these patients is a great challenge.

The role of angiogenesis in the development of highgrade gliomas (Tuettenberg, 2006) and its participation in the mechanism of resistance to radio- and chemotherapy through maintenance of glioma stem cells is well known (Calabrese; 2007). However, the capacity to monitor the angiogenic potential of brain tumors is not simple without invasive procedures, such as brain biopsies; therefore, the possibility of measuring pro-angiogenic potential in the CSF of brain tumor patients would have important implications. There are many pro-angiogenic mediators involved in cancer. Perhaps the most studied is VEGF. A tumor marker from cerebrospinal fluid (CSF) would be relevant in clinical practice, as it can be measured at different stages of the disease. In this study, as a first approach, we examined the pro-angiogenic activity of the LCE of patients in the in vivo model, the chick embryo chorioallantoic membrane assay.

\section{METHODS}

Patients

This study was performed according to the Helsinki Declaration. Informed consent approved by the local Ethics Committee of the Hospital Clínico de la Universidad de Chile was obtained for patients and healthy controls before their enrollment. All patients had a complete medical history and neuroradiological and pathologic diagnosis. CSF was drawn by lumbar puncture from two patients and during the craniotomy from three patients. With one patient, a sample was obtained during craniotomy and a second sample by lumbar puncture. CSF samples were obtained from four healthy age- and gendermatched controls, with normal neurological assessment and without any other neurological condition. The samples were 
obtained by lumbar puncture during elective knee surgery performed under spinal anesthesia. CSF samples were stored at $-20^{\circ} \mathrm{C}$ until the assay.

\section{CAM assay}

The host chick CAM assay was prepared as described by Ribatti, 2006. Briefly, White Leghorn fertilized eggs were kept in an incubator at $38.2{ }^{\circ} \mathrm{C}$ in a humidified atmosphere. At stage 20 (Hamburger, 1951) a square window was opened in the eggshell and $2 \mathrm{ml}$ of albumen was removed so that the developing CAM became detached from the shell, exposing the underlying blood vessels. The window was then sealed with clear adhesive tape and the host eggs were incubated undisturbed until the day of the experiment. Primitive CAM blood vessels proliferated and differentiated into arterial and venous systems until day 8 . Thus, a network of capillaries originated and migrated to occupy a particular area beneath the chorion and mediate gas exchanges with the outer environment. Rapid endothelial cell proliferation followed until day 12; thereafter, their mitotic index declined just as rapidly and the vascular system attained its final arrangement on day 18, just before hatching. Regarding the experimental conditions, on developmental day 8 , one sterilized methylcellulose disc $(5 \mathrm{~mm}$ in diameter, $0.25 \mathrm{~mm}$ pore size, $125 \mathrm{~mm}$ thick) per egg was instilled with $10 \mathrm{ul}$ of the CSF of patients and controls and sodium chloride $0.9 \%$ (physiological serum/ PS). The discs were placed on the surfaces of the growing CAM, in direct contact with a well-vascularized region. After the disc implantation, host eggs were incubated for another 48 hours. At day 10 of embryonic development, the implants and the surrounding embryonal tissue were surgically removed and fixed in 10\% formaldehyde. The tissues were processed using an autotechnicon apparatus with increasing concentrations of ethanol and infiltrated in paraffin (melting point $58-60^{\circ} \mathrm{C}$ ). Histological sections of $5 \mu \mathrm{m}$ thick were obtained from the sponges ante the underlying and immediately adjacent CAM portion, and stained with hematoxylin-eosin. The number of blood vessels under normal conditions was evaluated as the total number of micro-vessel (diameter ranging from 3 to $10 \mu \mathrm{m}$ ) intersections visualized in an area equivalent to $0.080 \mathrm{~mm} 2$ of the connective tissue. A blind, independent observer analyzed the CAM response.

The samples of the patients, control and physiological serum, were instilled in methylcellulose discs, one per egg on 5 eggs for each sample. The densities of blood vessels were compared to controls matched by age ( $<10$ years of difference) and gender and one sample of physiological serum. Control 1 was matched to three cases, given the difficulty of finding a healthy control for younger patients.

The statistical analysis was performed using the student $t$ test. A p value of $<0.05$ was considered significant.

\section{RESULTS}

We obtained CSF from six consecutive male patients aged between 25 and 67 years of age. The male:female ratio in high-grade gliomas is $3: 1$ in the population. The histological diagnoses were; glioblastoma in three patients, anaplastic oligodendroglioma in one patient and anaplastic ganglioglioma in two patients. CSF was obtained by LP from two patients, during the craniotomy from three patients and by both methods from one patient. We obtained CSF from four male patients, aged 29 to 61 . The sample was obtained by LP during spinal anesthesia, before the injection of the anaesthetic in patients that underwent knee surgery for meniscus repair or arthrosis of the knee (see Table I).

The three glioblastomas and one anaplastic ganglioglioma patients had de novo high-grade gliomas and two were secondary tumors developed from a previous low-grade tumor (anaplastic oligodendroglioma and one anaplastic ganglioglioma with a multicentric tumor). Two of our patients were previously treated with standard radio-chemotherapy with temozolomide (Stupp, 2005) and one, the multicentric

TABLE I

Patient characteristics

\begin{tabular}{|c|c|c|c|c|c|c|c|c|c|}
\hline Patient & Gender & $\begin{array}{l}\text { Age in } \\
\text { years }\end{array}$ & Diagnosis & De novo & Prior treatment & $\begin{array}{l}\text { CSF site of } \\
\text { extraction }\end{array}$ & $\begin{array}{c}\text { Capillaries } \\
\text { per Area } \\
\text { (Mean } \pm \\
\text { SE) }\end{array}$ & $\begin{array}{l}\text { Capillaries } \\
\text { per Area } \\
\text { in matched } \\
\text { control / } \\
(\text { Mean } \pm S E)\end{array}$ & P value \\
\hline 1 & male & 34 & Glioblastoma & yes & no & Surgery & $2.92 \pm 0.99$ & $2.29 \pm 0.99$ & $<0.05$ \\
\hline 2 & male & 63 & Glioblastoma & yes & no & Surgery & $3.91 \pm 1.61$ & $2.42 \pm 1.08$ & $<0.05$ \\
\hline 3 & male & 26 & Glioblastoma & yes & $\begin{array}{l}\text { Radiochemotherapy } \\
\text { with temozolomide }\end{array}$ & LP $3.41 \pm 1.14$ & & $2.01 \pm 0.98$ & $<0,05$ \\
\hline 4 & male & 29 & $\begin{array}{c}\text { Anaplastic } \\
\text { Oligodendroglioma }\end{array}$ & Prior O & $\begin{array}{l}\text { Radiochemotherapy } \\
\text { with temozolomide }\end{array}$ & LP $3.60 \pm 1.41$ & & $1.9 \pm 0.84$ & $<0.05$ \\
\hline 5 & male & 27 & $\begin{array}{c}\text { Anaplastic } \\
\text { Ganglioglioma }\end{array}$ & $\begin{array}{c}\text { Prior } \\
\text { GGWHOII }\end{array}$ & no & Surgery & $3.3 \pm 1.36$ & $2.01 \pm 0.98$ & $<0,05$ \\
\hline \multirow[t]{2}{*}{6} & male & 25 & $\begin{array}{c}\text { Analplastic } \\
\text { Ganglioglioma }\end{array}$ & yes & temozolomide & Surgery & $3.66 \pm 1.24$ & $2.01 \pm 0.98$ & $<0.05$ \\
\hline & & & & & & LP & $3.71 \pm 1.22$ & $2.01 \pm 0.98$ & $<0.05$ \\
\hline
\end{tabular}

Legend Table II: LP: lumbar puncture. O:Oligodendroglioma. GG: Ganglioglioma,WHO: World Health Organization. SE: Standard error. Capillaries per area: the count of capillaries intersections visualized in an area equivalent to $0.080 \mathrm{~mm} 2$. 
anaplastic ganglioglioma, with seven cycles of temozolomide interrupted because of hematologic toxicity. The patients' characteristics are detailed in Table I.

\section{CAM assay}

Higher density of microvessels was observed on the surface of the growing CAM two days after the implantation of methylcellulose discs impregnated with CSF from the patients with high-grade gliomas (mean 3.69 capillaries per area \pm 1.23 standard error) that was significantly higher compared to controls (mean 2.16 capillaries per area \pm 0.97 standard error) $\mathrm{p}<0.005$. No differences were observed between controls and physiological serum (mean 2.07 capillaries per area \pm 1.07 standard error), $\mathrm{p}=0.5$.

Each case was compared to a gender and age $(<10$ years of difference) matched control. The results for control 1 were matched to 3 cases. See details in Table I.

There were no differences between the CSF samples obtained by craniotomy ( 3.45 capillaries per area \pm 1.25 standard error) and those obtained by LP (3.57 capillaries per area \pm 1.26 standard error) $\mathrm{p}=0.81$. The angiogenic response to CSF of patient 6 with samples taken during craniotomy (3.66 capillaries per area \pm 1.24 standard error) and through LP (3.71 capillaries per area \pm 1.22 standard error) showed no difference. There was no difference between the CSF samples from the glioblastoma patients $(n=3)$ (3.41 capillaries per area \pm 1.25 standard error) compared the anaplastic ganglioglioma patient (3.48 capillaries per area \pm 1.3 standard error) $\mathrm{p}=0.87$. The samples from patients treated previously with chemotherapy $(n=2)$, with temozolomide $(n=1)$ (3.51 capillaries per area \pm 1.28 standard error), was not significantly different compared to those naive to therapy $(n=3)$ (3.38 capillaries per area \pm 1.32 standard error) $\mathrm{p}=0.54$.

\section{DISCUSSION}

It is widely recognized that angiogenesis is an important mechanism for glioma growth. The amount of vascularization is directly related to the degree of malignancy of the tumor (Leon, 1996) and the presence of VEGF in glioblastoma cells predicts a better radiological response with bevacizumab treatment, but not longer overall survival (Sathornsumetee, 2008).

There is great variability among tumor growth and therapy response rates among patients with the same tumor histology. The same tumor can reach escape mechanisms for antiangiogenic therapy as cooption to existing blood vessels (Holash, 2009; Rubenstein, 2000) and vascular mimicry of glioma cells (Hallani, 2010). Thus, a marker in an initial tissue sample does not give us information of possible newly acquired resistance mechanisms.

The CSF is produced in the choroids plexus and reabsorbed by arachnoid villi. Studies using radioisotopic tracers have shown a dynamic equilibrium of the CSF, the serum and the intercellular fluid of the brain and spinal cord [Ropper, 2005]. The classic CSF pattern of primary tumors is a mild rise of proteins. Thus, potentially the CSF of patients with primary brain tumors can contain angiogenic factors of the extracellular microenvironment of the glioma.

Despite the extended research on angiogenesis in highgrade gliomas, there have been only a few studies of angiogenesis in the CSF of patients. In low-grade gliomas, Ribon et al (2003) found neither PDGF nor VEGF in the CSF of 7 patients. Recently García-Navarrete (2003) detected higher concentrations of hepatocyte growth factor (HGF) in the CSF of 48 patients with high-grade glioma; a greater concentration prior to surgery was predictive of a shorter disease-free period.

Among pro-angiogenic factors, one of the best known is the vascular endothelial growth factor (VEGF) family (subtypes $\mathrm{A}, \mathrm{B}, \mathrm{C}$ and D and the placenta growth factor PIGF), which induces the endothelial cell to split, migrate and survive. The VEGF release can be induced in an epigenetic way by a series of factors such as hypoxia (mediated by the hypoxia induced factor), acid $\mathrm{pH}$, inflammatory cytokines (IL-6) and growth factors (bFGF, basic fibroblast growth factor) or it can also be directly released by the tumor cell. Sampath et al (2004) studied the presence of VEGF in the CSF of patients with high-grade gliomas and nonastrocytic tumors and found highly heterogeneous amounts among cases with the same histological grade (between $0-17.08 \mathrm{ng} \mathrm{VEGF} / \mathrm{mg}$ of total protein in glioblastoma). The samples obtained by LP showed less VEGF $(0.00-0.08 \mathrm{ng}$ VEGF/mg of total protein) than the samples from the ventricular system obtained in patients with external ventricular drains at the time of surgery (0.41-17.08 ng $\mathrm{VEGF} / \mathrm{mg}$ of total protein). Our results evidence a consistent pro-angiogenic activity of the CSF in all patients with highgrade glioma despite the site of the CSF sample. It must be considered that the Sampath patients had ventricular drainage for hypertensive hydrocephalus, which can be a confounder factor since ventricular drainage interferes with the normal flow of CSF. We compared CSF obtained by LP with that obtained from the brain cistern during surgery and not directly from the ventricular system. Finally, VEGF might not be the sole pro-angiogenic factor with biological activity present in CSF. Our results of pro-angiogenic activity in the CSF of highgrade gliomas could suggest the action of other pro-angiogenic factors in the CSF of patients with high-grade gliomas, such as, epidermal growth factor (EGF), angiopoietins (ang-1, -2, -3 and -4 that induces endothelial maturation through its TIE-2 receptor) and platelet-derived growth factor (PDGF), which stabilizes the neoformed vessel acting in a pericyte level. These findings show us the opportunity to study in the future the biologic angiogenic balance of the CSF as a result of numerous known and currently unknown mediators at different stages of the disease.

Angiogenesis is an important mechanism for high-grade glioma growth and resistance to well established therapies. Further studies are needed to find specific mediators in the CSF and possible prognostic and predictive markers for a better clinical assessment of patients.

\section{ACKNOWLEDGEMENTS}

This study was supported by the grant "Iniciación" I08/082 of the "Vicerrectoría de Investigación y Desarrollo" of the Universidad de Chile and the grants "Temas Libres" 324/08 of the "Oficina de apoyo a la investigación" of the Hospital Clínico de la Universidad de Chile.

\section{REFERENCES}

CALABRESE C, KOCAK M, HOGG TL, FULLER C, HAMMER B, OH EY, GABER MW, FINKELSTEIN D, ALLEN M, FRANK A, BAYAZITOV IT, 
ZAKHARENKO SS, GAJJAR A, DAVIDOFF A, GILBERTSON RJ (2007) A Perivascular Niche for Brain Tumor Stem Cells. Cancer Cell 11: 69-82.

FRIEDMAN AH, FRIEDMAN HS (2007) Bevacizumab Plus Irinotecan in Recurrent Glioblastoma Multiforme. J Clin Oncol 25: 4722-4729.

FRIEDMAN H, WEN P, MIKKELSEN T, SCHIFF D, ABREY LE, YUNG WKA, PALEOLOGOS N, NICHOLAS MK, JENSEN R, VREDENBURGH J, HUANG J, ZHENG M, CLOUGHESY T (2009) Bevacizumab alone and in combination with irinotecan in recurrent glioblastoma. J Clin Oncol 27: 4733-40.

GARCIA-NAVARRETE R, ARRIETA O, SOTELO J (2010) Hepatocyte growth factor in cerebrospinal fluid is associated with mortality and recurrence of glioblastoma, and could be of prognostic value. J Neurooncol 97: 347351.

HALLANI SE, PEGLION F, ROUSSEAU A, COLIN C, IDBAIH A, MARIE Y, MOKHTARI K, THOMAS JL, EICHMANN A, DELATTRE JY, MANIOTIS AJ, SANSON M (2010) A new alternative mechanism in glioblastoma vascularization: tubular vasculogenic mimicry. Brain 133: 973-982.

HAMBURGER V (1951) A series of normal stages in the development of the chick embryo. J Morphol 88: 49-92.

HOLASHA J, COMPTON D, ET AL (1999) Vessel cooption, regression, and growth in tumors mediated by angiopoietins and VEGF. Science 284: 1994-98.

KREISL TN, MOORE K, DUIC P, ROYCE C, STROUD I, GARREN N, MACKEY M, BUTMAN JA, CAMPHAUSEN K, PARK J, ALBERT PS, FINE HA (2009) Phase II trial of single-agent bevacizumab followed by bevacizumab plus irinotecan at tumor progression in recurrent glioblastoma. J Clin Oncol 27: 740-5.

LEON SP, BLACK PM (1996) Microvessel density is a prognostic indicator for patients with astroglial brain tumors. Cancer 77: 362-72.

LUYKEN C, FIMMERS R, URBACH H, WIESTLER O, SCHRAMM J (2004) Supratentorial Gangliogliomas: Histopathologic Grading and Tumor
Recurrence in 184 Patients with a Median Follow-Up of 8 Years. Cancer 101: 146-155.

RIBATTI D, VACCA A, PRESTA M (2006) The gelatin sponge-chorioallantoic membrane assay. Naturs protocols 1: 85-91.

RIBOM D, PIETRAS K, SMITS A (2003) Growth factor analysis of low-grade glioma CSF: PDGF and VEGF are not detectable. Neurol Sci 24: 70-73.

ROPPER A, BROWN R (2005) ADAMS AND VICTORS Principles of Neurology. $8^{\text {th }}$ ed. Massachusett: McGraw-Hill. Pp - 530.

RUBENSTEIN JL, OZAWA T, ET AL (2000) Anti-VEGF antibody treatment of glioblastoma prolongs survival but results in increased vascular cooption. Neoplasia 2: 306-14.

SAMPATH P, SUNGARIAN A, CORTEZ S, ALDERSON L, STOPA EG (2004) Cerebrospinal Fluid (Vascular Endothelial Growth Factor) and Serologic (Recoverin) Tumor Markers for Malignant Glioma. Cancer Control 11: 174-180.

SATHORNSUMETEE S, MARCELLO JE, HERNDON II JE, MCLENDON RE, DESJARDINS A, FRIEDMAN HS, DEWHIRST MW, VREDENBURGH JJ, RICH JN (2008) Tumor Angiogenic and Hypoxic Profiles Predict Radiographic Response and Survival in Malignant Astrocytoma Patients Treated With Bevacizumab and Irinotecan. J Clin Oncol 26: 271-278.

STUPP R, ET AL (2005) Radiotherapy plus concomitant and adjuvant temozolomide for glioblastoma. N Engl J Med 352: 987-96.

STUPP R ET AL (2009) Effects of radiotherapy with concomitant and adjuvant temozolomide versus radiotherapy alone on survival in glioblastoma in a randomised phase III study: 5-year analysis of the EORTC-NCIC trial. Lancet Oncol 10: 459-466.

TUETTENBERG CF, VAJKOCZY P (2006) Angiogenesis in malignant glioma-A target for antitumor therapy? Crit Rev Oncol Hematol 59: 181193

VREDENBURGH JJ, HERNDON II JE, JENNIFER M, REARDON DA, OUINN JA, RICH JN, SATHORNSUMETEE S, GURURUANGAN S, SAMPSON J, WAGNER M, BAILEY L, BIGNER DD, 